16 | InterAção

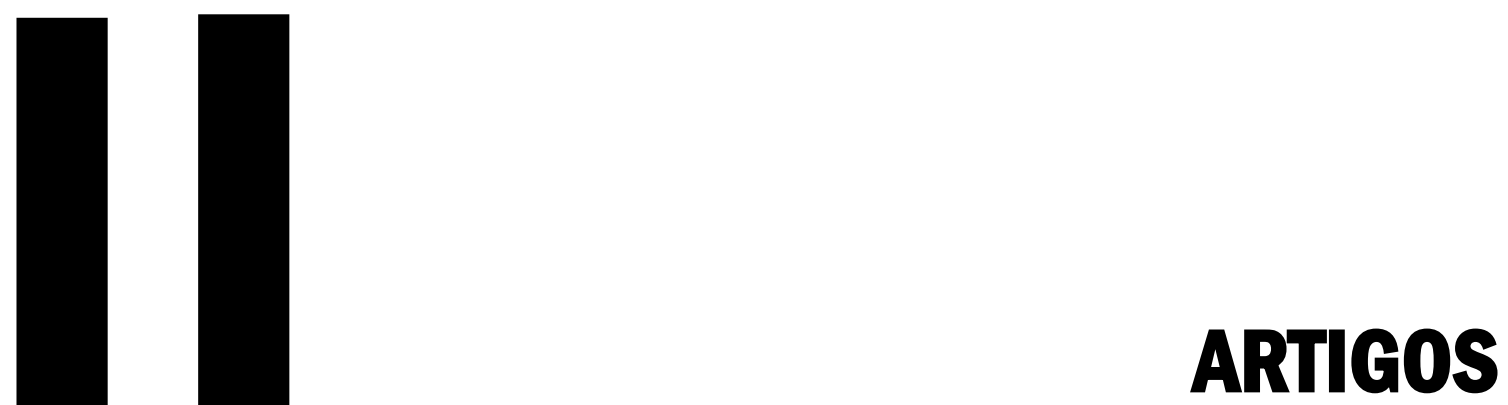




\title{
A POLÍTICA INTERNA BRASILEIRA DE PROTEÇÃO AOS REFUGIADOS, APÁTRIDAS E VÍTIMAS DE TRÁFICO DE PESSOAS: $O$ CASO DO COMIRAT
}

\author{
Gustavo Oliveira Lima Pereira
}

Tatiana de Almeida Freitas Rodrigues Squeff

\section{Resumo}

Os Comitês Estaduais de Refugiados são órgãos com o objetivo de dar assistência humanitária para migrantes, especialmente no que tange a elaboração de um plano estadual de políticas de atenção às pessoas em situações de vulnerabilidade, a fim de garantir o acesso desse público à políticas públicas. Nesse sentido, durante o seminário de Mobilidade Humana, em outubro de 2012, foi criado o Comitê Estadual de Refugiados do Estado do Rio Grande do Sul (COMIRAT) para a proteção de refugiados, apátridas e vítimas de tráfico de pessoas, notadamente para prestar assistência humanitária a estas pessoas. Em vista disso, este texto busca apontar as bases fundamentais que sustentam a construção do COMIRAT e problematizar os seus pontos de maior mérito, qual seja, o de ampliar a discussão sobre o refúgio para também a figura do apátrida, notando as formas de atuação do Estado no tratamento dos fluxos migratórios e o acolhimento de vulneráveis na sociedade.

Palavras-chave: COMIRAT; Apátridas; Refugiados; Acolhimento; Hospitalidade

\begin{abstract}
The State Refugee Committees are bodies constituted with the objective of providing humanitarian assistance to migrants, especially regarding the elaboration of a state plan of policies designated to provide care for persons in situations of vulnerability, in order to guarantee the public access to public policies. In this sense, during the Human Mobility Seminar, in October 2012, the State Committee for Refugees of Rio Grande do Sul state (COMIRAT) was established in order to protect of refugees, stateless persons and victims of trafficking in persons, particularly to provide humanitarian assistance to these people. Therefore, this text seeks to point out the fundamental bases that support the construction of COMIRAT and to problematize its points of greatest merit, that is, to extend the discussion about the refuge to also the figure of the stateless person, noting the forms of action of the State in the treatment of migratory flows and the reception of the vulnerable in society.
\end{abstract}

Keywords: COMIRAT; Stateless people; Refugees; Reception; Hospitality. 
18 InterAção

\section{INTRODUÇÃO}

Durante o seminário de Mobilidade Humana, em outubro de 2012, foi criado o Comitê Estadual de Refugiados do Rio Grande do Sul para Proteção de Refugiados, Apátridas e Vítimas de Tráfico de Pessoas (COMIRAT) com o objetivo de dar assistência humanitária a estas pessoas. Dentre os principais papéis do Comitê se concentra a elaboração do Plano Estadual de Políticas de Atenção às pessoas nas situações mencionadas, contribuindo e ampliando o acesso desse público às políticas públicas.

Muito embora seja o quarto Comitê Estadual no Brasil com esta atribuição humanitária, ressalta-se a forte ação do Rio Grande do Sul na questão do refúgio. Vale repisar que a primeira atuação brasileira frente à proteção internacional aos refugiados no âmbito do reassentamento ${ }^{1}$ ocorreu em 2002, na cidade de Porto Alegre, quando o país acolheu o primeiro grupo de reassentados afegãos. Nesse viés, destaca-se o pioneirismo do Estado na tutela de vulneráveis que se encontram em mobilidade, abrangendo não apenas o migrante comum e o refugiado, mas também os apátridas.

O reassentamento voluntário deve ser entendido como a situação na qual o refugiado não conseguiu ou não pôde permanecer no Estado que reconheceu seu status de refugiado, por não conseguir se adaptar aos costumes do país ou outras conjunturas que tornam arriscado sua permanência nele. É possível o reassentamento também para poder ficar mais próximo de familiares que auxiliariam no auxílio emocional ao reassentado. Assim, surge a figura de um terceiro país, que se dispõe voluntariamente a acolher o refugiado, pois a postura de país acolhedor pela via do reassentamento não faz parte do

\footnotetext{
10 pioneirismo mencionado diz respeito somente ao reassentamento, pois Rio de janeiro e São Paulo já atuavam na proteção dos refugiados desde os anos 70.
} 
19 | InterAção

conteúdo vinculativo estabelecido pelos Tratados Internacionais envolvendo o tema. O ACNUR presta auxílio ao refugiado reassentado, proporcionando amparo financeiro como também a interlocução política entre os países envolvidos.

A Declaração e o Plano de Ação do México (PAM) de 2004 é o documento regional que reconhece e estabelece estratégias para avançar a proteção de refugiados na região. Entre as estratégias estabelecidas pelo PAM, o reassentamento destaca-se como solução inovadora para diminuir o impacto que alguns países vêm sofrendo pelo fluxo massivo de refugiados em seus territórios.

O Brasil tem exercido papel fundamental no desenvolvimento e implementação do Programa de Reassentamento Solidário na América Latina, como parte do Plano de Ação do México. Desde 2002, o Brasil reassentou mais de 500 refugiados, a maior parte deles colombianos, dentre os quais $47 \%$ são mulheres. Em dezembro de 2010, POR EXEMPLO, celebrando o $60^{\circ}$ aniversário do ACNUR, o Brasil sediou um encontro governamental onde 18 países da América Latina se comprometeram a se engajar mais para a proteção das vítimas de deslocamentos forçados e apátridas na região (BRASIL, 2013).

A Noruega é considerada o país mais tradicional em termos de reassentamento (ANNONI; VALDES, 2012, p. 139). O Brasil vem se tornando um país emergente, tanto na integração local quanto no reassentamento, criando Comitês Estaduais de Refugiados. O CONARE estabeleceu um prazo de 72 horas, em caráter urgente, para decidir sobre os pedidos de reassentamento, quando as circunstâncias envolvem necessidades de proteção especial (ANNONI; VALDES, 2012, p. 156-157). 
$20 \mid$ InterAção

Os Comitês Estaduais de Refugiados são órgãos com o objetivo de dar assistência humanitária para migrantes, refugiados, apátridas e vítimas de tráfico de pessoas. Dentre os principais papéis dos Comitês, concentra-se a elaboração do Plano Estadual de Políticas de Atenção às pessoas nas situações mencionadas, contribuindo e ampliando o acesso desse público às políticas públicas.

Dentre os objetivos deste artigo, portanto, problematizar-se-á o COMIRAT e de seus pontos de maior mérito: o de ampliar a discussão sobre o refúgio para também a figura do apátrida ${ }^{2}$. O fenômeno da apatridia passa muitas vezes a margem das discussões que giram em torno do Direito Internacional dos Direitos Humanos apesar de ser, como tentar-se-á brevemente demonstrar, o exato ponto cego dos direitos humanos e onde é necessário uma reestruturação de sua base de fundamentação para enfim angariar resultados práticos.

Na primeira parte deste texto, algumas reflexões que dizem respeito ao fenômeno dos refugiados e da apatridia serão trazidos à baila, bem como o modo que abertura ética para uma hospitalidade incondicional pode representar um ponto de partida revigorador na dinâmica dos direitos humanos. No segundo momento, uma dimensão mais prática será realizada, abordando a atuação do Estado no tratamento dos fluxos migratórios como aparato de acolhimento e cooperação internacional.

\footnotetext{
2 Em virtude de se tratar de um Comitê muito novo, deteremo-nos a uma análise mais no âmbito conceitual, dando ênfase primordial ao fenômeno da apatridia, previsto no ordenamento do COMIRAT. Não teremos espaço aqui para desenvolver de forma mais aprofundada a também importante questão do tráfico de pessoas.
} 
21 InterAção

\section{HOSPITALIDADE E ACOLHIMENTO: 0 DIREITO INCONDICIONAL DE MIGRAR.}

Como ponto de partida, entendem-se as políticas de proteção internacional dos direitos humanos tendo como pressuposto o que aqui chamase de direito incondicional de migrar. Ou seja, a possibilidade incessante de estar em segurança em qualquer lugar do planeta, com os devidos direitos assegurados e a condição de ter a diferença intercultural reconhecida. No plano dos direitos humanos, a temática se torna espinhosa, já que tal direito incondicional de migrar é sempre posto em cheque em nome da segurança nacional e do inarredável conceito tradicional de soberania, que ainda toma conta das principais concepções que tangem o Direito Internacional e as relações internacionais (ŽIŽEK, 2003, p. 9).

O direito incondicional de migrar só é possível de ser pensado a partir de uma certa ampliação da ideia de hospitalidade. Desenvolvida primeiramente por Immanuel Kant, para quem o problema não era cognitivo, mas sim moral, a hospitalidade estaria pautada na liberdade enquanto um imperativo categórico, devendo ser respeitada por ser um dever (KANT, 2008, p. 64). Entretanto, esta ideia de hospitalidade, quando atualizada pelos escritos de Jacques Derrida, vai muito além desse dever moral Kantiano, sento entendida enquanto uma "obrigação única que cada um de nós tem com o outro" - tornando-se incondicional (PEREZ, 2007, p. 26 ).

O COMIRAT tem como horizonte de sentido de atuação a proteção dos direitos humanos para fazer valer o direito incondicional de migrar para migrantes, refugiados, apátridas e vítimas de tráfico de pessoas. Neste sentido, atua com esse fundamento de legitimidade: o de angariar políticas de proteção humanitária em nome de uma ideia de hospitalidade para além das cartilhas e das meras boas intenções - abarcando o visitante absolutamente estranho e 
22 InterAção

inesperado. Intenta, portanto, agir com a realidade concreta das pessoas que sentem na pele a ausência dos direitos.

Uma das grandes inovações do COMIRAT está em fazer menção a situação do apátrida, que é exatamente o "curto circuito" do sistema dos direitos humanos. Afinal, como falar em um direito incondicional de migrar daquele que nem reconhecido como nacional é/está por nenhum Estado? Como pensar a situação da apatridia e do refúgio sem reivindicar a própria reconstrução da ideia de hospitalidade? Como pensar a circunstância dos fluxos migratórios sem percorrer os caminhos da teoria de base que os fundamentam?

No plano do Direito Internacional dos Direitos Humanos, há uma diferenciação entre a figura do apátrida e do refugiado que é necessário aqui ressaltar. Apátridas são pessoas consideradas sem pátria, situação esta que ocorre ou em virtude da política interna de países que retiram a cidadania de determinados seres humanos por critérios discricionários (como foi o caso ocorrido na Segunda Guerra Mundial, onde o primeiro ato dos nazistas contra os judeus foi o de retirar a cidadania alemã destes) ou pelos critérios de distribuição da nacionalidade de cada país ${ }^{3}$. Essa circunstância existencial repercute de inúmeras formas na vida do ser humano desprovido de nacionalidade, como as dificuldades de acesso à saúde pública, impossibilidades imigratórias e a própria exclusão de determinados atos da vida civil.

Já o refugiado, segundo a Convenção sobre o Estatuto dos Refugiados de 1951 e o Protocolo Adicional de 1967, é o nacional de um país que precisa fugir de seu Estado-nação e buscar proteção internacional em outro território soberano em virtude de bem fundado temor de perseguição por motivos

\footnotetext{
${ }^{3}$ Os clássicos critérios referenciados pela sistemática internacional são ou do solo (jus soll) ou do sangue (jus sangunis), este segundo também chamado de critério da filiação, cabendo também aos países inserirem-se em um sistema misto como é o caso do Brasil. Não é cabido aqui aprofundar-se a discussão nesta direção.
} 


\section{3 | InterAção}

discriminatórios, normalmente baseados na cor, religião, nacionalidade, pertencimento a algum grupo social ou opinião política, ou que sendo apátrida tenha bem-fundado temor de perseguição em seu país de residência habitual. Isso porque, já é aceito perante a comunidade internacional a ideia de um indivíduo ter que buscar outro Estado para refugiar-se por força de violações maciças de direitos humanos ${ }^{4}$.

Por conseguinte, são notáveis as diferenças entre ambas as circunstâncias geradoras de migração forçada, porém, sob o ponto de vista prático, segundo Hannah Arendt (1990, p. 314), em inúmeras situações o problema concreto vivenciado por apátridas e refugiados torna a diferenciação embaraçada. Nessa ordem de ideias, pois, há tanto em um quanto no outro, a destruição dos "direitos básicos do homem enquanto ser humano capaz de direitos e obrigações" (LAFER, 1988, p. 109), ou seja, a morte da sua personalidade jurídica (ARENDT, 1990, p. 498), no sentido da ruptura de seu vínculo normal com o Estado, e muitas vezes, do impedimento de sua cidadania, ou de seu “direito a ter direitos" (ARENDT, 1990, p. 298).

Com base nos números e estatísticas de refugiados e apátridas no mundo disponibilizadas pelo Alto Comissariado das Nações Unidas para Refugiados (ACNUR) - órgão da $\mathrm{ONU}^{5}$, bem como na visível insuficiência dos mecanismos de proteção internacional para proteger imigrantes ilegais, apátridas, refugiados e deslocados internos 6 , entende-se que é necessária uma

\footnotetext{
${ }^{4}$ Ao menos, é o que prescrevem certos documentos regionais, como no plano americano (Declaração de Cartagena de 1984) e africano (Convenção acerca de Aspectos Específicos dos Problemas de Refugiados na África de 1969), os quais podem levar ao reconhecimento de uma regra costumeira eminentemente internacional, além de diversos juristas, cujos entendimentos igualmente corroboram para a aceitação mundial de uma definição alargada de refugiado (ALMEIDA, 2001, p. 155-167; G00DWILL-GILL; MCADAM, 2007, p. 90-91).

${ }^{5}$ Segundo o ACNUR, são 35.440 .128 pessoas que se encontram em situações de refúgio, apatridia, deslocamento forçado, entre outras, ao final de 2011 (ACNUR, 2011).

6 Pode-se aqui citar como exemplo a política de combate a imigração ilegal na Europa, pela 'Diretiva de Retorno', também conhecida como "diretiva da vergonha" e nas políticas imigratórias estadunidenses, que remetem a prisão
} 
$24 \mid$ InterAção

desconstrução dos pressupostos clássicos dos direitos humanos e a reconstrução de seus pressupostos não através da ideia de universalismo, mas sim pela compreensão de uma hospitalidade incondicional, capaz de compreender o problema em sua concretude mais sofisticada.

\section{O RECONHECIMENTO DA DIFERENÇA ENTRE APÁTRIDAS E REFUGIADOS.}

Hannah Arendt, afirma que a diferenciação entre apátridas e refugiados se dá pelo primeiro se caracterizar pelo fato de não ter nacionalidade, enquanto o segundo é determinado por não estar amparado pela proteção diplomática. Entretanto, esclarece que para fins práticos na maioria dos casos diferença é irrisória, pois todos os refugiados, de algum modo, são apátridas na esfera política, sendo essa aproximação também é apropriada nos dias atuais (ARENDT, 1990, p. 314).

Para ela, o contínuo estado de instabilidade que demarcava o âmbito de uma Europa sempre a beira da destruição em massa, do período entre guerras até o final da Segunda Guerra Mundial, resultou na migração de diversos grupos humanos, que, na esperança de consolidar suas liberdades de expressão ou simplesmente a permanência de suas vidas, abandonavam seus países de origem. Isso determinou um destino insólito: além de não terem mais lares, agora já não tinham mais direitos humanos, ou qualquer outro direito (ARENDT,1990, p, 300).

A diversidade entre culturas tornou-se algo tão comum neste período europeu que muitas vezes não era possível identificar a origem de determinada

instantânea aos solicitantes de refúgio, sustentados pela política de combate ao terrorismo em nome da soberania nacional, após 011 de setembro. 
25 | InterAção

pessoa. Cunhou-se, assim, a rotulação de displaced persons (pessoas deslocadas) àqueles que estavam à margem da lei ordinária. Segundo Arendt, a expressão "foi inventada durante a guerra com a finalidade única de liquidar o problema dos apátridas de uma vez por todas, por meio do simplório expediente de ignorar a sua existência" (ARENDT,1990, p. 313). Mas essa perspectiva reconhecia ao menos o fato de que essas pessoas haviam perdido a proteção de seus governos e requeriam acordos internacionais para salvaguardar sua condição de cidadãos.

O não reconhecimento da condição de apátrida abriu caminho para a repatriação forçada, ou seja: a deportação do refugiado político para seu país de origem. Em muitos casos esse país se negava a reconhecê-lo como cidadão, ou utilizava essa reintegração involuntária para castigar o refugiado (ARENDT, 1990, p. 318). Nem por um instante se pode notar o direito à hospitalidade perante estrangeiros, tão sonhado por Kant no seu conhecido projeto de paz perpétua (KANT, 2008, p. 43).

Todos esses problemas determinaram as falhas das tentativas de repatriação e naturalização. Assim sendo, mesmo reconhecida a impossibilidade de deportação de uma pessoa, por meio de tratados, na prática isso não impedia um Estado de expulsá-la de suas fronteiras limítrofes. Esse "homem sem Estado" - um legítimo "fora da lei" - era agora tido como uma anomalia que não adentrava na estrutura legislativa normal de nenhum país.

Ele agora estava sujeito ao arbítrio da polícia, que não hesitava em cometer atos ilegais para diluir o número de indesejáveis no país. Conforme Arendt (1990, p. 317), “o Estado, insistindo em seu soberano direito de expulsão, era forçado, pela natureza ilegal da condição de apátrida, a cometer atos confessadamente ilegais". O apátrida, sem direito a residência e ao 
26 | InterAção

trabalho, naturalmente, acabava tendo que subverter a lei para poder sobreviver.

$\mathrm{Na}$ questão dos apátridas do período das guerras mundiais, a criminalização da tentativa de sobrevivência de tais grupos acabou sendo a primordial manifestação da indiferença para com a humanidade. O apátrida

[...] estava sujeito a ir para a cadeia sem jamais cometer um crime. Mais que isso, toda a hierarquia de valores existentes nos países tidos como civilizados era invertida nesse caso. Uma vez que ele constituía a anomalia não-prevista na lei geral, era melhor que se convertesse na anomalia que ela previa: o criminoso (ARENDT, 1990, p. 319).

A humanidade, tendo muitas vezes sua imagem concebida como uma família de nações, finalmente agora se deparava com esta realidade, mas de forma avessa a qualquer ideal humanitário. Conforme Arendt (1990, p. 327), uma pessoa expulsa de uma comunidade encontrava-se expulsa de toda a família de nações. Ser expulso de um país era ser expulso do mundo. O ser-queestá-no-mundo passa a ser o ser-que-tangencia-o-mundo em suas arestas; o vazio de ser que preenche a crise de sentido da humanidade. É a redução do outro ao nada.

Nestes casos, a calamidade não está nos velhos problemas dos direitos humanos, ou seja, direito à vida, à liberdade de expressão, igualdade perante a lei ou qualquer espécie de direito específico; mas no fato de essas pessoas já não pertencerem a nenhuma comunidade. "Sua situação angustiante não resulta do fato de não serem iguais perante a lei, mas sim de não existirem mais leis para eles; não de serem oprimidos, mas de não haver ninguém mais que se interesse por eles, nem que seja para oprimi-los" (ARENDT, 1990, p. 329).

Essa percepção revela o fracasso das concepções, sejam elas naturalistas ou racionalistas, que reverenciam os direitos humanos como sinal de uma 
27 InterAção

suposta existência de um ser humano em si, domado pela sua essência, pois este homem puro, como vimos, perdeu todas as suas qualidades especificas e relacionais ao se tornar um meramente humano. Como assevera Hannah Arendt (1990, p. 333),

[o] conceito de direitos humanos [...] desmoronou no mesmo instante em que aqueles que diziam acreditar nele se confrontaram pela primeira vez com seres que haviam realmente perdido todas as outras qualidades e relações específicas - exceto que ainda eram humanos. O mundo não viu nada de sagrado na abstrata nudez de ser unicamente humano.

Esta afirmação confirma a insuficiência na qual, muitas vezes, a noção de dignidade da pessoa humana, tida em uma dimensão teórico-abstrata, naufraga. Ter a dignidade abstratamente reconhecida, sem que isso implique alguma inserção concreta no universo das relações, acaba soando como um mero adorno retórico e uma saída tangencial para a profundidade do problema.

Neste sentido, propõe-se aqui, ancorado pelo pensamento de Jacques Derrida, uma visão de hospitalidade incondicional que contemple a dimensão das situações concretas das pessoas envolvidas. Circunstância que se almeja como a base que sustentará o COMIRAT, justamente pela sua pontualidade em reconhecer a necessidade de outros migrantes forçados a alcançarem seus direitos mínimos.

\section{COSMOPOLITISMO E HOSPITALIDADE INCONDICIONAL}

Todo e qualquer aparato jurídico, como também é o caso do COMIRAT em tela, não pode dinamizar o seu campo de atuação tão somente pela premissa formal e pelo mero delineamento de regras. Por mais que o campo formal seja 
28 InterAção

importante, ele ainda opera de acordo com condicionamentos. Isto Derrida chamou de leis da hospitalidade, ou seja, uma hospitalidade condicionada a regra e a formalidade, sempre cobrando uma contra partida.

Em face a hospitalidade condicional, Derrida contrapõe com aquilo que denomina de "hospitalidade pura e incondicional" - uma manifestação de loucura e verdadeira transgressão da lógica do contrato, pressupondo a recepção da alteridade; onde abrem-se as portas para alguém que não é esperado nem convidado, para o "absolutamente estrangeiro", para o sem destino ou sem pátria, para o "imprevisível, em suma, totalmente outro" (DERRIDA, 2003, p. 137).

Isso porque, não haveria um convite na hospitalidade incondicional, $\mathrm{o}$ qual não estaria regrado à uma série de adaptações, como, por exemplo, às leis e os costumes do território "alheio", mas tão somente a hospitalidade em si. Por esse viés, é inconcebível haver um dever de hospitalidade (Kantiano), cuja ocorrência se daria pela solicitação de hospitalidade em línguas (e direitos) comuns as quais se está acostumado no local em que se encontra o estrangeiro (DERRIDA, 2003, p. 15). Derrida entende que, em tais condições, não haveria estrangeiro, pois este deveria ser alguém absolutamente estranho - não identificável e imprevisível - que é recebido mesmo quando não convidado ou esperado (DERRIDA, 2003, p. 26).

Contudo, o drama se traduz por este status de hospitalidade (incondicional) ser impossível de se legislar ou organizar institucionalmente, “pois reduziria o problema a um cálculo cognitivo" (PEREZ, 2007, p. 25), muito embora somente seja possível se pensar jurídica e politicamente a partir desse conceito. Em outras palavras, queremos dizer que a hospitalidade incondicional é uma aventura da subjetividade e não uma proposta jurídica, apesar de toda proposta subjetiva ser a condição de se pensar o jurídico. 
29 | InterAção

Para nós, concordando com Derrida, A possibilidade de se pensar a hospitalidade é o que permite compreender o mundo de forma cosmopolita. Afinal, a hospitalidade incondicional se concentra em pensar o político para além do político, a partir de uma nova internacionalidade; a partir de um cosmopolitismo - agora reinventado. Um cosmopolitismo para além do cosmopolitismo político pensado pelo ideário iluminista, pois este cosmopolitismo está condicionando pela soberania do Estado; está estruturado pelos limites jurídico-políticos (BERNARDO, 2002. p. 437).

Nesse sentido, esclarece Derrida (apud BERNARDO, 2002, p. 139):

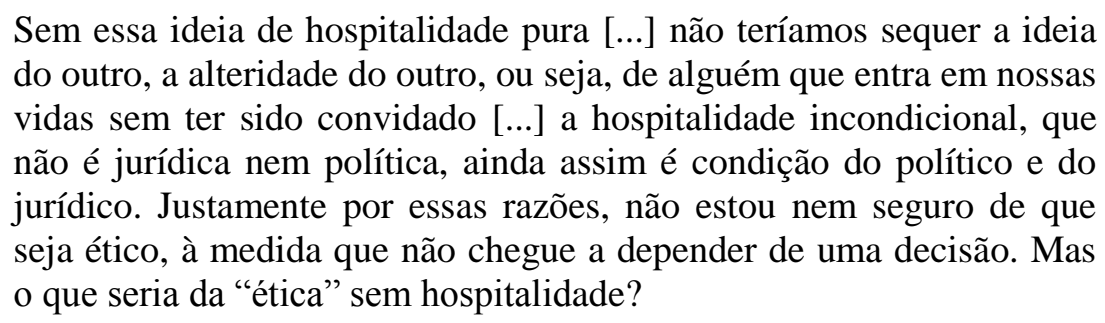

Assim, para dar-se concretude de significado aos Comitês Regionais, é preciso de algum modo reinventar a ideia de cidadania, algo que perpassa por uma reinvenção da própria hospitalidade universal. A reinvenção da cidadania, de algum modo significa, até mesmo, negar a idéia de cidadania, para se obter uma dimensão cosmopolita novel a partir de uma solidariedade internacional, a qual reconheça as migrações enquanto problema humanitário eminentemente mundial.

Afinal, não obstante o cosmopolitismo tradicional "ainda sup[or] a instância do Estado e do cidadão, ainda que seja cidadão do mundo" (DERRIDA, 2004, p. 317-318), atualmente, nenhum Estado, partido, sindicato ou organização de cidadãos se incumbe verdadeiramente do problema - o qual poderá ser revertido com a ideia dos Comitês Regionais, sobretudo, o rio- 
$30 \mid$ InterAção

grandense, por alargar o entendimento de 'estrangeiro', tornando-o mais próximo do ideal Derridiano.

\section{O TRATAMENTO DOS FLUXOS MIGRATÓRIOS PELO ESTADO}

Desde meados do século $X X$, a migração está muito presente na agenda mundial, atraindo a atenção de diversos estudiosos por afetar abruptamente a realidade tanto econômica quanto política e social dos países que recebem influxos, tornando-se um tema de grande interesse mundial, pois geradora de grandes desafios (HILY, 2003). Afinal, hodiernamente, "as pessoas vão de um país para o outro em grande número", como bem frisa Jean-Claude Chesnais (1994), carregando consigo uma bagagem cultural muitas vezes distinta daquela que encontrarão em outro território.

Muito embora essa troca de tradições e hábitos possa favorecer a evolução da sociedade, justamente por enriquecer uma dada localidade, não são raros os casos de dificuldades sentidas por migrantes quanto a sua recepção e adaptação. Isso, pois, receber seres humanos sem os quais haja uma ligação intrínseca, tal como é aquela formada pelo indivíduo e o Estado que lhe atribuíra nacionalidade de forma originária, não tem se mostrado uma tarefa fácil para os governantes, os quais ainda prezam pelo seu "legítimo direito westfaliano de proteger suas fronteiras" (NASCIMENTO, 2012, p. 24) impedimento este que é totalmente contrário à hospitalidade pura.

Entende-se por migração, o ato de transpassar a barreira políticogeográfica de um Estado por mínimo lapso temporal (CASTELS, 2000, p. 269281), enquanto migrante é aquele indivíduo que "fixa residência em um país distinto daquele seu de origem por mais de um ano" (GLOBAL COMMISSION 
31 InterAção

ON INTERNATIONAL MIGRATION, 2005, p. viii). Ocorre que esses indivíduos podem ser tanto migrantes voluntários quanto forçados classificação esta considerada essencial para o presente texto, principalmente face ao direito humano de beneficiar-se de abrigo quando diante de uma situação de necessidade, prescrito na Declaração Universal dos Direitos Humanos (ONU, 1948, art. 147).

O migrante voluntário, especificamente, é aquele que tem a intenção de mudar o país de sua residência habitual espontaneamente, de modo legal ou irregular, buscando uma melhor oportunidade de trabalho ou estudo, como também mais qualidade de vida, ou por outra motivação pessoal. Por outra banda, o migrante forçado é aquele que não tem alternativa se não abandonar o Estado em que se encontra (normalmente aquele com o qual possui vínculo de nacionalidade), buscando tutela em outro, em virtude de uma situação de violência, coerção, opressão/exploração, necessidade vital ou perseguição baseada em cor, nacionalidade, religião, grupo social ou opinião política.

Dentre os diversos desafios que envolvem as migrações internacionais, com certeza a tutela deste grupo de migrantes forçados se destaca, não apenas por se tratar de vulneráveis, isto é, pessoas que já se encontram em uma situação fragilizada, mas por esses mesmos indivíduos serem mais suscetíveis a violações de direitos humanos, sejam estas cometidas por parte do Estado ou por homens que se aproveitam da sua situação delicada, as quais os deixam as margens da sociedade, e por precisarem efetivamente das ideias de hospitalidade.

Hannah Arendt já alertava que a clandestinidade é um grande empecilho para a efetivação dos direitos humanos, dada a impossibilidade de transformar

\footnotetext{
${ }^{7}$ Art. 14: (1) Toda pessoa, vítima de perseguição, tem o direito de procurar e de gozar asilo em outros países. (2) Este direito não pode ser invocado em caso de perseguição legitimamente motivada por crimes de direito comum ou por atos contrários aos propósitos e princípios das Nações Unidas (ONU, 1948).
} 
32 InterAção

tais migrantes em "cidadãos" no sentido clássico, isto é, enquanto participantes do meio social, detentores de direitos (ARENDT, 1990, p. 314). Entretanto, ao aproximar o Estado à hospitalidade Derridiana, enaltecendo a solidariedade internacional, poder-se-ia desenvolver a potencialidade dos migrantes, fazendo-os contribuir de forma positiva para o novo meio social no qual encontram-se implantados - finalmente tendo, conhecendo e usufruindo de direitos.

Nesse escopo, o papel dos Estados faz-se imperativo na gestão das migrações, haja vista serem eles os entes capazes de reconhecer direitos e garantir a proteção dos vulneráveis, promovendo, assim, a assistência humanitária e o desenvolvimento humano.

\section{O DEVER DOS ESTADOS FRENTE ÀS MIGRAÇÕES}

Muito embora fosse mais fácil transitar nos tempos mais primórdios entre as diversas nações, forte nas navegações e no sentimento expansionista e desbravador do homem, atualmente há muito mais um fechamento das fronteiras dos Estados do que a sua própria abertura. Entretanto, situações de violência generalizada, de perseguições constantes e de exploração latente, fazem com que os indivíduos busquem outros territórios para habitar, mesmo com tantas barreiras impostas pelos Estados.

Inclusive, submetem-se a situações desumanas e cruéis para verem-se dentro de um determinado Estado, imaginando estarem protegidas em seu interior - o que muitas vezes não ocorre frente à inércia estatal para com a edição de políticas públicas que, ao menos, garantam as um tratamento mínimo, condizente com os parâmetros internacionais. Contudo, se as 
33 | InterAção

migrações internacionais denotam a abertura das fronteiras dos países, de modo que estes recebam indivíduos e garantam plenamente a eles seus direitos fundamentais, tais como fornecem aos seus próprios nacionais, não estaria o Estado cometendo um ilícito internacional em não agir nesses moldes?

A inobservância de uma obrigação internacional por certo país, de fato, é considerada um ilícito internacional. Para tanto, todavia, é necessário afirmar qual seria a obrigação afastada pela conduta do ente no que tange as migrações, que pode vir a ser a própria falta de solidariedade internacional, exteriorizada no dever de cooperação dos Estados, prescrita na Carta das Nações Unidas $\left(\mathrm{ONU}, 1945^{8}\right)$.

Esse dever, nomeadamente, “orienta a realização de [...] políticas relativas ao objetivo de bem-comum, inerente à razão constituidora do Estado", as quais impõem "uma adequação entre os interesses mais significativos", em prol da proteção dos direitos humanos (DERANI, 1997, p. 157). A cooperação entre os povos, logo, transpassa as necessárias "regras de coordenação" entre os Estados (MENEZES, 2007, p. 210), exigindo um comprometimento maior de todos os integrantes da sociedade internacional a perseguir os objetivos considerados comuns, como é a proteção dos direitos humanos (NASSER, 2005, p. 204).

Por conseguinte, os Estados têm um dever de não apenas auxiliar os demais países na proteção de direitos humanos de vulneráveis (ALSTON; QUINN, 1987, p. 213), como deve também agir de modo a proteger esses direitos no seu território por ser a assistência humanitária à migrantes forçados um interesse comum de toda a comunidade internacional. Essa prescrição,

\footnotetext{
${ }^{8}$ Art. 1: Os objetivos das Nações Unidas são: [...] [3] Realizar a cooperação internacional, resolvendo os problemas internacionais de caráter econômico, social, cultural ou humanitário, promovendo e estimulando o respeito pelos direitos do homem e pelas liberdades fundamentais para todos, sem distinção de raça, sexo, língua ou religião (ONU, 1945).
} 
34 InterAção

inclusive, abarca a doutrina da "Responsabilidade de Proteger" na qual se insere o 'Dever de Proteger', a qual estabelece que a concretização de direitos basilares do homem requer ações positivas do Estado, especialmente daqueles aonde os indivíduos vulneráveis estão situados, como forma de expressar a solidariedade internacional, prestando o devido amparo (SHUE, 1980, p. 52).

Nesse sentido, considerando que tais migrantes estão em situação de fragilidade social, uma resposta concreta do Estado não é só esperada, como também obrigatória. Afinal, “o Estado existe para o ser humano, e não ao contrário", como bem coloca Cançado Trindade (2008, p. 31). Além disso, é inerente a este ente clássico de Direito Internacional Público, que tem aguçado o senso de hospitalidade pelo alto influxo de migrantes, o dever de agir "com espírito de fraternidade", tal como ressalta a própria Declaração Universal dos Direitos Humanos (ONU, 1948, Art. 19).

Ponto culminante do exercício desde dever de cooperação frente às migrações, portanto, é a oportuna criação do COMIRAT. Isso porque, ele tem o condão de fomentar a inserção dos vulneráveis no seio social a partir do seu reconhecimento, evitando situações que geram derrogações de direitos humanos, como a clandestinidade Arendtiana, ressaltando a própria indiferença em tal indivíduo ser um estrangeiro, no sentido Derridiano do termo, para ver garantido seus direitos.

\footnotetext{
9 Art. 1: Todas as pessoas nascem livres e iguais em dignidade e direitos. São dotadas de razão e consciência e devem agir em relação umas às outras com espírito de fraternidade (ONU, 1948).
} 
35 | InterAção

\section{0 COMIRAT E A HOSPITALIDADE DERRIDIANA}

A formulação de um Comitê Regional para migrantes forçados no Rio Grande do Sul - COMIRAT - não é inédito no Brasil, tendo esse sido, como mencionado, o quarto órgão destes moldes criado no país para amparar os interesses de não-nacionais. Seguindo os exemplos de São Paulo, Rio de Janeiro e Paraná, o Rio Grande do Sul implantou seu comitê no final do mês de outubro de 2012, amparado pelo Decreto Estadual n. 49.729 (BRASIL, 2012), objetivando igualmente ter um espaço público para fortalecer e auxiliar migrantes forçados, fazendo com que não só estes conheçam os direitos e benefícios a que tem direito, mas toda a sociedade civil.

Composto por representantes de vários segmentos do governo e da sociedade civil, o COMIRAT, como anteriormente apontado, é o primeiro comitê do país a trazer ao seu campo de atuação os apátridas, além dos refugiados e das vítimas de tráfico de pessoas. Por isso, apresenta uma importância imensa para o respeito e a promoção dos direitos humanos de indivíduos vulneráveis que chegam ao Brasil pelo Rio Grande do Sul, ou, chegando em outro Estado brasileiro, optem ou sejam remetidos ao Estado gaúcho.

No preâmbulo do Decreto supramencionado, percebe-se que o ideal que pautou a sua implantação, além de resguardar os direitos básicos do homem, era justamente o de promover o acesso dos migrantes ao meio social, garantindo um espaço antes desconhecido na sociedade para a promoção e idealização de políticas públicas voltadas a tais pessoas. Designadamente, é o teor do preâmbulo: 
36 | InterAção

[procura-se por meio do Comitê] adequar instrumentos legislativos e fortalecer instâncias de elaboração e ações da política que garantam e assegurem o acesso aos imigrantes e aos refugiados e propiciem a atualização o debate sobre ações dirigidas à mobilidade humana conforme os princípios constitucionais que garantem a dignidade humana.

Para tanto, além de elaborar, implementar e monitorar um 'Plano Estadual de Políticas de Atenção a Migrantes, Refugiados e Vítimas de Tráfico de Pessoas no Estado do Rio Grande do Sul', o COMIRAT apoiará a promoção de ações voltadas a integração desses migrantes forçados no estado e agirá como um centro coletor de denúncias, dado que lhe foi atribuída a competência de informar às instancias competentes sobre a ocorrência de violações, para fins de apuração e responsabilização.

Surge dessa forma, um expoente da hospitalidade pura Derridiana, visto que o Estado do Rio Grande do Sul esta(rá) preparado para receber visitantes absolutamente estranhos e inesperados, os quais adentram o território de forma forçosa e sofrem com a ausência de direitos. O COMIRAT, nesse condão, age como articulador, o qual garante uma esperança palpável aos migrantes vulneráveis, em nome da solidariedade internacional que engloba o tema.

\section{CONSIDERAÇÕES FINAIS}

O direito internacional de migrar é uma regra atribuída a todos os seres humanos conforme a Declaração Universal dos Direitos Humanos (ONU, 1948, Art. $1^{10}$ ). Afinal, ninguém é obrigado a ficar dentro do seu próprio território, principalmente quando situações preocupantes no que tange a proteção dos

${ }^{10}$ Art. 13 - 1. Toda pessoa tem direito à liberdade de locomoção e residência dentro das fronteiras de cada Estado. 2. Toda pessoa tem o direito de deixar qualquer país, inclusive o próprio, e a este regressar (ONU, 1948). 
37 InterAção

direitos humanos estão em jogo, como situações de graves violações de direitos e perseguições baseadas em algum tipo discriminatório.

Assim, o ser humano que precisa migrar, já preocupado com a sua segurança no seu local de origem, não deveria igualmente atormentar-se quanto a possibilidade de seus direitos não serem respeitados ou as garantias mínimas não serem atendidas no Estado receptor. Entretanto, esta é a grande problemática hodierna dos direitos humanos - a de estar em segurança em qualquer lugar do planeta, com os devidos direitos assegurados e a condição de ter a diferença intercultural reconhecida.

Com esse intuito, o presente texto buscou analisar a hospitalidade sob o viés da filosofia de Jacques Derrida, exprimindo que há uma obrigação incondicional em todos os seres humanos de receber estrangeiros mesmo quando não sejam esperados ou convidados, não podendo haver uma simples desconsideração para com os seus direitos ou, até mesmo, a sua alienação do meio social.

Viu-se que, por tal perspectiva, deve-se tutelar o estrangeiro da mesma forma como se protege os nacionais em um determinado Estado, afinal, a partir de uma solidariedade internacional, reinventa-se a cidadania, agora com uma dimensão cosmopolita, a qual não só reconhece as migrações internacionais enquanto problema humanitário eminentemente mundial, mas também prescreve o dever de cooperar para acabar com os problemas oriundos da marginalização dos migrantes forçados - muito mais vulneráveis e suscetíveis a derrogações de direitos.

Ao cabo, como forma de materializar os deveres do Estado perante a comunidade internacional frente às migrações, abordou-se a criação do COMIRAT, não apenas pela sua pontualidade em reconhecer a necessidade de 
38 InterAção

outros migrantes forçados a alcançarem seus direitos mínimos - tais como os apátridas -, como igualmente pelos seus objetivos, quais sejam, promover o respeito para com os direitos humanos desses indivíduos e promover políticas públicas para trazer o "estrangeiro" para dentro da proteção jurídica do Estado que o acolhe, mostrando-lhe os benefícios e os direitos aos quais tem direito, com base no Direito Internacional.

\section{REFERÊNCIAS}

ACNUR. Estatísticas. 2011. Disponível em:

<http://www.acnur.org/t3/portugues/recursos/estatisticas/>. Acesso em 01 jan. 2017.

ANNONI, Dannielle. VALDES, Lysian Carolina. O direito internacional dos refugiados e o Brasil. Curitiba: juruá, 2012.

ALMEIDA, Guilherme. A lei 9.474/97 e a definição ampliada de refugiado. In: ARAUJO, Nadia. O Direito Internacional dos Refugiados: uma perspectiva brasileira. Rio de Janeiro: Renovar, 2001.

ALSTON, Philip; QUINN, Gerard. The nature and scope of State parties' obligations under the International Covenant on Economic, Social and Cultural Rights. Human Rights Quarterly. n. 9, pp. 156-229, 1987.

ARENDT, Hannah. Origens do Totalitarismo: Anti-semitismo, imperialismo e totalitarismo. São Paulo: Companhia das Letras, 1990.

BERNARDO, Fernanda. A ética da hospitalidade, segundo J. Derrida, ou o porvir do cosmopolitismo por vir a propósito das cidades-refúgio, re-inventar a cidadania. Revista Filosófica de Coimbra. n. 22, pp. 421-446, 2002.

BRASIL. Secretaria da Justiça, Trabalho e Direitos Humanos do Paraná. Dados sobre Refúgio no Brasil. 2013. Disponível em:

<www.dedihc.pr.gov.brhttp:/ / www.dedihc.pr.gov.br/modules/noticias/artic le.php?storyid=2629\&tit=Dados-sobre-refugio-no-Brasil $>$, acesso em 12 jul. de 2017. 
39 | InterAção

BRASIL. Decreto Estadual do Rio Grande do Sul n. 49.729. Out. 2012. Disponível em: <http://www.ans.gov.br/texto_lei.php?id=1738>, acesso em julho de 2017

CANÇADO TRINDADE, Antônio A. Desarraigamento e a proteção dos migrantes na legislação internacional dos direitos humanos. Revista da Faculdade de Direito - UFPR. n. 47, pp. 29-64, 2008.

CARDOSO, Tatiana de A.; PAGANINI, Nicole. A Migração Internacional: o problema dos Direitos Humanos e o Caso da Comunidade Europeia. Curitiba: Anais da I Jornada Brasileira de Direito Internacional, 2009.

CASTELS, Stephen. International Migration at the Beginning of the TwentyFirst Century: Global Trends and Issues. International Social Sciences Journal. UNESCO, n. 165, 2000.

CHESNAIS, Jean-Claude. Os fluxos dos povos: A migração internacional como uma força revolucionária. Braudel Papers. nº 9, Set./Out., 1994.

DERANI, Cristiane. Direito Ambiental Econômico. São Paulo: Max Limonad, 1997.

DERRIDA, Jacques. Filosofia em tempo de terror. Diálogos com Habermas e Derrida. BORRADORI, Giovanna (Org.) Rio de Janeiro: Jorge Zahar editor, 2003.

DERRIDA, Jacques. Papel-máquina. São Paulo: Estação liberdade, 2004.

DERRIDA, Jaques. Anne Dufourmantelle convida Jaques Derrida a falar da Hospitalidade. São Paulo: Escuta, 2003.

GLOBAL COMMISSION ON INTERNATIONAL MIGRATION. Migration in an interconnected world. 2005. Disponível em:

<http://www.queensu.ca/samp/migrationresources/reports/gcim-completereport-2005.pdf >. Acesso em 10 jan. 2017.

GOODWILL-GILL, Guy; MCADAM, Jane. The Refugee in International Law. $3^{\mathrm{a}}$ Edição. New York: Oxford University Press, 2007.

HILY, Marie-Antoinette. As migrações contemporâneas: dos Estados e dos homens. Apresentado no Seminário Cultura e Intolerância. São Paulo, 2003.

KANT, Immanuel. A Paz Perpétua. Porto Alegre: L\&PM Pocket, 2008.

LAFER, Celso. A Reconstrução dos Direitos Humanos: um diálogo com o pensamento de Hannah Arendt. São Paulo: Companhia das Letras, 1988.

MENEZES, Wagner. Direito Internacional na América Latina. Curitiba: Juruá, 2007. 
40 InterAção

NASCIMENTO, Blenda. Os fluxos migratórios internacionais e as fronteiras impermeáveis. Universitas Relações Internacionais. v. 10, n.2, pp. 23-42, 2012.

NASSER, Salen H. Desenvolvimento, Costume Internacional e Soft Law. In: AMARAL JUNIOR, Alberto (org.). Direito Internacional e Desenvolvimento.

Barueri: Manole, 2005.

ONU. Carta das Nações Unidas. 1945.

ONU. Resolução 217 da Assembleia Geral (Declaração Universal dos Direitos Humanos). 1948.

PEREIRA, Gustavo Oliveira. A Pátria dos sem Pátria: Direitos Humanos \& Alteridade. Porto Alegre: Ed. UniRitter, 2011.

PEREZ, Daniel. Os significados dos conceitos de hospitalidade em Kant e a problemática do estrangeiro. Konvergencias, Filosofia y Culturas en Diálogo. a. IV, n. 15, pp. 23-34, 2007(2).

SHUE, Henry. Basic Rights: subsistence, affluence and US Foreign Policy. New Jersey: Princeton University Press, 1980.

ŽIŽEK, Slavoj. Bem-vindo ao deserto do real! São Paulo: boitempo, 2003. 